\title{
Reliability Analysis of Vertical Well Casing: Comparison of API 5C3 and ISO 10400
}

\author{
Amirah Husna Abdul Halim ${ }^{1, *}$, Zahiraniza Mustaffa ${ }^{1}$, and Do Kyun Kim ${ }^{1}$ \\ ${ }^{1}$ Civil \& Environmental Engineering Department, Universiti Teknologi PETRONAS, 32610 Perak, \\ Malaysia
}

\begin{abstract}
Well casings are designed against burst strength pressure. The same formula is used in determining the remaining burst strength pressure of casing that suffered from wear. API 5C3 and ISO 10400 burst strength models are widely used to determine the burst strength pressure and the remaining strength of casing. This paper focus on the comparison of both burst strength models for its reliability assessment for vertical well casing. The limit state design method was used and adapted into this study to calculate the probability of failure for both burst strength models. The reliability analysis for both models is conducted using Monte Carlo simulation. The results show that ISO 10400 burst strength model can predict the probability of failure for vertical well casing when subjected to higher operating pressure compared to API $5 \mathrm{C} 3$ burst strength model. ISO 10400 burst strength model can predict probability of failure for higher operating pressure due to adaption of ultimate tensile strength as the strength parameter in the equation whereas API 5C3 has adopt yield strength as the strength parameter in the equation.
\end{abstract}

\section{Introduction}

In petroleum industry, various drilling methods had been introduced over the years. Some of drilling methods that exists in the industry is horizontal drilling, vertical drilling and directional drilling. Compared to other drilling methods, vertical well drilling has been one of the most popular in drilling oil and gas reservoir. Casing system is a major structural system in a vertical well made up of several components, such as casing in different sizes and production tubing. Casing play an important role in keeping the integrity of wellbore [1]. Casings are used to protect production tubing conduits during drilling, production and workover operations. It is also used in protecting the groundwater and aquifers found in nearby well from being contaminated by the extracted hydrocarbon. Normally, casing will be installed first before production tubing is placed inside, using expendables packing devices.

Wells with high hydrogen sulphide content, high pressure and high temperature can cause the surrounding environment of casing to be more complicated. It can affect the external and internal pressures applied towards casing [2]. The surrounding environment will become more severe and the pressures imposed to casing will be increased [2]. Casing should have adequate strength to resist all the pressures without having any failure. Generally, casings are designed against burst pressure by taking a safety margin between

\footnotetext{
* Corresponding author: amirahhusna389@gmail.com
} 
calculated stresses and yield strength of the material [3]. Usually, in a vertical well, the main loadings experienced by casing are internal pressure, external pressure and axial force. Their modes of failure are usually depended upon burst and collapse pressure [1].

\section{Burst strength equations of casing}

Casing burst strength can be predicted based on its modes of failure which are ductile instability and brittle fracture [4]. In 1998, Parslay, Cernocky and Wink [5] have developed equations in predicting the burst strength of casing based on the ductile instability. Then, Tallin et al. [6] has come up with a simple criterion in determining the types of casing failure; ductile or brittle failure. Over the years, there were numerous studies done by previous researchers about the strength of casing, as well as developing a limit-state design procedures in calculating the remaining strength of vertical well casing [6]-[9]. Mathematical modelling based from API 5C3 [10] standard and ISO 10400 [11] standard were used to calculate the strength design of vertical well casing. In determining the remaining burst strength of well casing, the same formula is also used for the calculation of its remaining strength.

\subsection{API 5C3 internal pressure strength model}

The American Petroleum Institute (API) bulletin 5C3 [10] has provided an equation to calculate the casing burst strength, $P_{b}$ as given in Eq. (1),

$$
P_{b}=0.875\left(\frac{2 \sigma_{y} t}{D}\right)
$$

where $D$ is the nominal outside diameter, $t$ is the nominal wall thickness, and $\sigma_{y}$ is the yield strength.

API 5C3 strength model can predict the serviceability limit state (SLS) of casing under elastic regime. By considering Barlow's equation for burst strength design, it has made the basic failure criterion of API 5C3 depended upon the initial yield of inner wall surface under internal pressure. It also made API $5 \mathrm{C} 3$ to predict the minimum internal pressure strength of casing.

\subsection{ISO 10400 burst strength pressure under capped-end conditions}

The standard code of ISO 10400 were proposed based from the works of Klever and Stewart [3], [12]. The mathematical expression is given as the following:

$$
P_{b}=\frac{2 \sigma_{U T S}}{\left(\frac{D}{0.875 \times t}\right)-1}\left[\left(\frac{1}{2}\right)^{1+n}+\left(\frac{1}{\sqrt{3}}\right)^{1+n}\right]
$$

where $\sigma_{U T S}$ is the ultimate tensile strength of casing, $t$ is the minimum wall thickness, $D$ is the outside diameter and $n$ is the dimensionless hardening exponent used to obtain a curve fit of stress-strain curve from the uniaxial tensile test (taken as 0.26).

ISO 10400 strength model adapted the ultimate limit state (ULS) philosophy into the calculation of burst strength of casing under internal pressure. In comparison to the API 5C3 standard, the ISO 10400 burst strength model can forecast the burst strength of casing much better. It is stated that ISO 10400 burst strength model give a better prediction on the 
casing burst failure compared to API 5C3burst strength model as it adopts and used the minimum wall thickness and ultimate tensile strength as one of its parameters in the equation [5], [6], [13].

\section{Structural reliability analysis}

Structural reliability model and stress analysis is usually conducted using three different ways; deterministic, semi-probabilistic ad probabilistic method. For deterministic method, allowable stress design (ASD) is usually used in determining the reliability model. As for semi-probabilistic method, load factor design (LFD) is usually adapted and used in designing the reliability model. On the other hand, for probabilistic method, load and resistance factor (LRFD) is used in determining and modelling the reliability analysis model. In this paper, the probabilistic method is being adapted and used to model the reliability analysis for vertical well casing. A limit state function model, some random variables and a reliability method will be used in analysing the structural reliability of vertical well casing. The objective of reliability analysis is to estimate the probability of failure for vertical well casing when the frequency cannot be observed directly [6].

Reliability analysis is usually based on the idealisation of the failure limit, called a limit state function. The limit state function is a function of several variables which can affect the failure of pipe such as material strength, wall thickness and outer diameter of the pipe. In general, limit state function will give a positive values for sae events and negative values for failure events [1]. The general equation for limit state function is:

$$
Z(X)=R(X)-S
$$

where $Z(X)$ is the limit state function model, $R(X)$ is the resistance or strength term and $S$ is the load term. $X$ is a vector containing random variables which can impact the burst strength of casing. The limit state function will give a positive value for a safe events and negative values for failure events. The failure events will occur when $R(X)<S$ or $Z(X)<0$, while the safe events occur when $R(X)>S$ or $Z(X)>0$. For casing burst strength pressure, the resistance parameter will be both burst strength pressure models; API $5 \mathrm{C} 3$ and ISO 10400 standards, while the load parameter will be operating pressure of the casing. Equations (4) and (5) show the limit state function for casing burst strength pressure for both burst pressure models, respectively.

$$
\begin{gathered}
Z(X)=0.875\left(\frac{2 \sigma_{y} t}{D}\right)-P_{o p} \\
Z(X)=\left\{\frac{2 \sigma_{U T S}}{\left(\frac{D}{0.875 \times t}\right)-1}\left[\left(\frac{1}{2}\right)^{1+n}+\left(\frac{1}{\sqrt{3}}\right)^{1+n}\right]\right\}-P_{o p}
\end{gathered}
$$

where $P_{o p}$ is the casing operating pressure (MPa).

Figure 1 shows curves of strength and load probability density function. In the figure, the shaded area is overlaying part of two curves which called as interference region where failure occurs. The smaller area of interference region, the higher the reliability; otherwise, the reliability of failure is low [14]. 


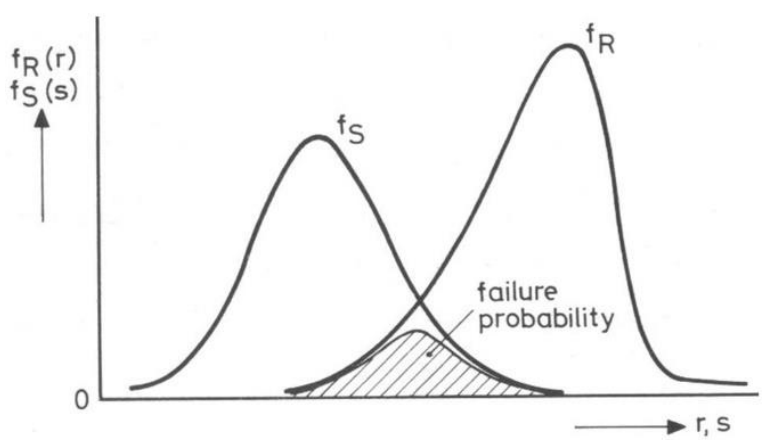

Fig.1. The interference region in probability density function

Monte Carlo simulations are used in this paper to perform the probabilistic analysis. In this simulation, a $n$ random of scenarios need to be performed to be tested in the limit state function, computing the number of failure events $n_{f}$ (when $Z(X) \leq 0$ ), and estimate the failure probability by $P_{f}=n_{f} / n$. The random scenarios are defined by generating $n$ aleatory values for each random variable assumed in the analysis. Therefore, the statistical characterisation of each variable and a random number generator will be required [1]. By its nature, Monte Carlo simulations provides an accurate result since an adequate number of simulations is performed. This technique is well suited for estimating the probabilities that are between $1 \%$ to $99 \%$ [6]. However, Monte Carlo method will have issues on the low failure probabilities. If the problem has a probability of failure equals to $10^{-6}$ scenarios should be generated and simulated [1].

\section{Application of data in the model}

All parameters and variables used Eq. (4) and (5) are considered and to be treated randomly. Based on the previously established limit state function that utilised the API 5C3 and ISO 10400 burst equations, the simulation were done to estimate the probability of failure for vertical well casing. All calculations and simulations were done using MATLAB programming language. A vertical well casing as shown in Figure 2 was selected to find out its probability of failure. 


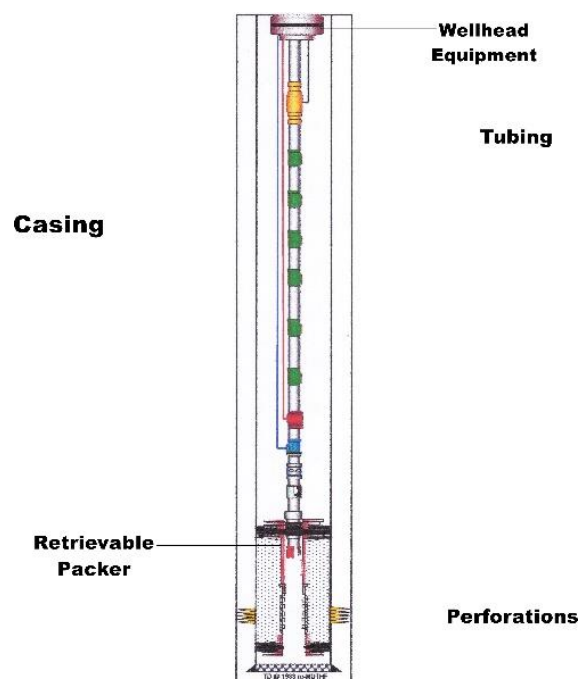

Fig. 2. Schematic diagram of vertical well casing

The vertical well was taken from ABU-A3 well which was located in the Offshore Peninsula Malaysia. The water depth for this well was around $63 \mathrm{~m}$ and depth of the well was around $1896 \mathrm{~m}$ deep. Casing used in this well was grade L-80 steel casing pipe. The diameter of the casing was $7^{\prime}$ inch $(177.8 \mathrm{~mm})$ while the size of the intermediate casing was around 9.625 inch $(244.475 \mathrm{~mm})$. Table 1 shows the summary of random variables data used for the calculation of casing burst strength in Eq. (1) and (2).

Table 1: Summary of the random variables used for Eq. (1) and (2)

\begin{tabular}{|c|c|c|c|c|}
\hline Parameters & $\begin{array}{c}\text { Mean } \\
(\mu)\end{array}$ & $\begin{array}{c}\text { Standard } \\
\text { Deviation }(\sigma)\end{array}$ & $\begin{array}{c}\text { Probability } \\
\text { Distribution } \\
\text { Function (PDF) }\end{array}$ & References \\
\hline$\sigma_{y}(\mathrm{MPa})$ & 552 & 38.64 & Normal & Chantose et al., [15] \\
\hline$t(\mathrm{~mm})$ & 88.9 & 6.22 & Weibull & $\begin{array}{l}\text { API 5C3 [16] } \\
\text { Chantose et al., [15] }\end{array}$ \\
\hline$D(\mathrm{~mm})$ & 177.8 & 17.78 & Weibull & $\begin{array}{l}\text { API 5C3 [16] } \\
\text { Chantose et al., [15] }\end{array}$ \\
\hline$\sigma_{U T S}(\mathrm{MPa})$ & 655 & 43.59 & Normal & Chantose et al., [15] \\
\hline$P_{o p}(\mathrm{MPa})$ & $\begin{array}{l}300- \\
1000\end{array}$ & $30-100$ & Normal & \\
\hline
\end{tabular}

\section{Results and discussion}

By using data provided in Table 1, the probability of failure for the vertical well casing for both burst strength models were estimated. Figure 3 and 4 show the interference region of both burst strength models. From the comparison of both limit state function models, burst strength equation from API 5C3 standard seems to have a lower failure region compared to burst strength of ISO 10400 standard. For API 5C3 standard, the failure area is situated at a lower region which is around 450 to 750 whereas the failure area of ISO 10400 standard is situated around 700 to 850 . As the failure area of the model is situated at lower region, the casing is expected to be failed under lower operating pressure. However, compared to burst strength equation of ISO 10400 standard, the density function is situated at a higher region 


\section{ICCOEE 2018}

and the failure area was quite smaller compared to API 5C3 burst strength model. It means that the casing can be expected to be failed at a higher operating pressure if the reliability assessment were done using ISO 10400 burst strength model as the resistance.

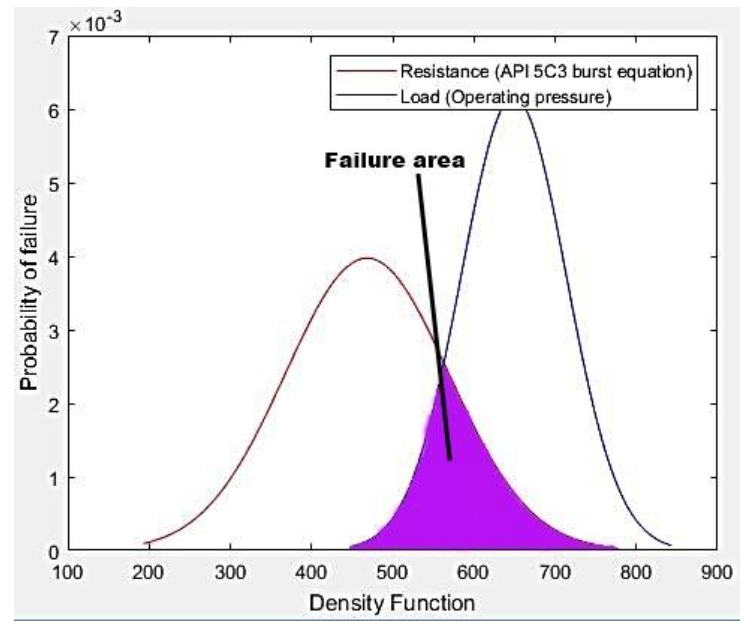

Fig. 3. Interference region of $\mathrm{Z}$ for $\mathrm{API} 5 \mathrm{C} 3$ burst strength equation with operating pressure

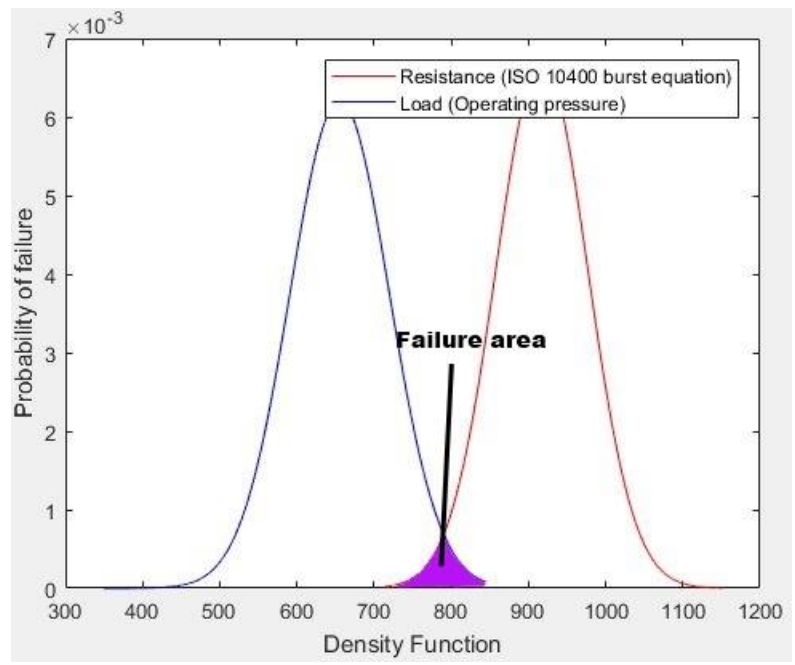

Fig. 4. Interference region of $Z$ for ISO 10400 burst strength equation with operating pressure

For API 5C3 burst strength model, when the operating pressure of vertical well were subjected to $650 \mathrm{MPa}$, the probability of failure is recorded around $9.98 \times 10^{-4}$. On the other hand, for ISO 10400 burst strength model, when subjected with the same operating pressure, the probability of failure is recorded around $2.0 \times 10^{-6}$. This means API $5 \mathrm{C} 3$ burst strength model has a higher probability of failure compared to ISO 10400 burst strength model. Further analysis in finding out the reliability analysis of both burst strength models when subjected to different operating pressure ranging from $300 \mathrm{MPa}$ to $1000 \mathrm{MPa}$. 


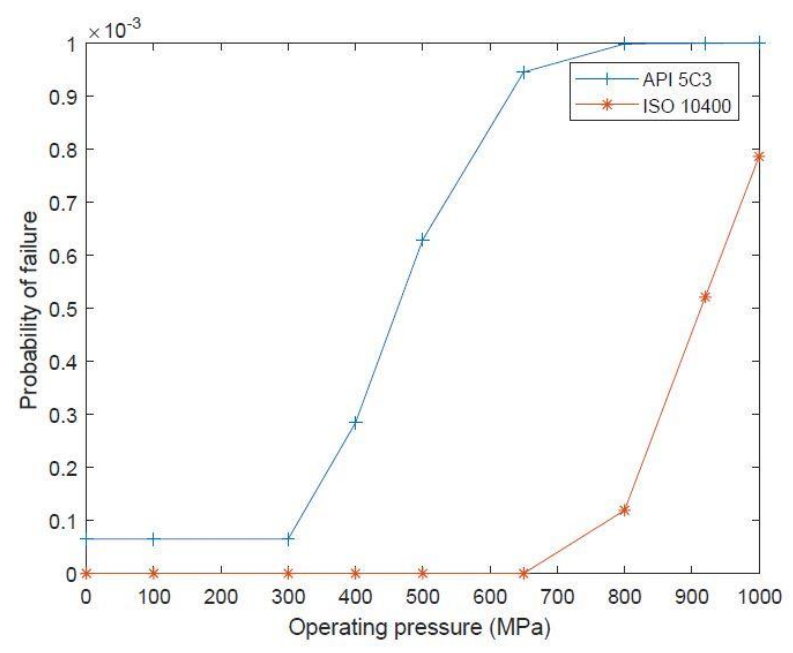

Fig. 5. Failure probability under different operating pressure for both burst strength models

Based from the figure above, the probability of failure of well casing increases significantly as the operating pressure increases for both burst strength models. The failure probability subjected to API 5C3 burst strength model reach the highest probability when it is subjected to operating pressure of $780 \mathrm{MPa}$. On the other hand, the failure probability that were subjected to ISO 10400 burst strength model were still lower as the operating pressure keep on increasing. Since ISO 10400 burst strength model use ultimate tensile strength as its strength parameter, it can predict a higher probability of failure compared to API 5C3 burst strength model. However, ISO 10400 burst strength model cannot predict the probability of failure when subjected to lower operating pressure. It seems that only API 5C3 burst strength model can predict probability of failure when subjected to lower operating pressure. This is because yield strength can be subjected to lower pressure whereas ultimate tensile strength can be subjected to higher operating pressure. Theoretically, it is closely related to the theory of stress-strain curve of a steel pipe. In the stress-strain curve, the deformation of pipe will occur first at the yield strength point. As the pressure keeps increasing, the deformation will occur at the highest point, which is ultimate tensile strength point. After this point, the deformation will be decreasing and occur in the fracture stress point. The same theory can be applied for the probability of failure for both burst strength models based from the results obtained. Based from the results, the probability of failure for API 5C3 burst strength model will failed at lower operating pressure as it adopts yield strength as its strength parameter in the equation. On the other hand, the probability of failure for ISO 10400 burst strength model can withstand a higher operating pressure as it used ultimate tensile strength as its strength parameter. It is known that ultimate tensile strength can withstand higher pressure compared to yield strength.

\section{Conclusions}

In this paper, the conventional casing assessment method is done by applying burst strength model as the resistance and operating pressure of the well as the load factor. All parameters used in this paper are set as constants determined randomly distributions. In the assessment on the reliability of vertical well casing, based from the results from both burst strength models, it can be said that ISO 10400 burst strength model may have given a slightly better assessment compared to API 5C3 burst strength model. Casing burst strength model of ISO 
10400 can predict a probability of failure for the casing if a higher operating pressure is subjected towards the casing in the future. In comparison of the two burst strength models, ISO 10400 burst strength model used ultimate tensile strength as its strength parameter in the equation while API 5C3 used yield strength as its strength parameter in the equation. The used of ultimate tensile strength as strength parameter in the equation has made ISO 10400 burst strength model to be slightly better than API 5C3 burst strength model. Reliability-based analysis is useful for the industry in identifying the quantity of well casing for future used.

For future recommendation, the need of a detailed analysis that consists of both burst strength models and load pressure can be done. The factors of pore pressure in the well, fracture pressure, mud density and kick intension can be considered together in the load factors, $S$. As for the resistance factor, $R(X)$, the strength of casing itself, the external loads and internal loads applied on the casing can be considered for a detailed analysis in the future.

\section{References}

1. L. P. Gouveia, E. T. Lima Junior, J. P. L. Santos, J. L. R. Anjos, and W. W. M. Lira, "Realibility-Based Study of Well Casing Strength Formulation," in ICCM, 2014.

2. Y. Lin et al., "Burst Strength of Tubing and Casing Based on Twin Shear Unified Strength Theory," PLoS One, vol. 9, no. 11, 2014.

3. F. J. Klever and G. Stewart, "Analytical Burst Strength Prediction of OCTG With and Without Defects," Soc. Pet. Eng., no. 48329, 1998.

4. X. Huang, Y. Chen, K. Lin, M. Mihsein, K. Kibble, and R. Hall, "Burst Strength Analysis of Casing With Geometrical Imperfections," J. Press. Vessel Technol., vol. 129, no. 4, p. 763, 2007.

5. P. R. Paslay, E. P. Cernocky, and R. Wink, "Burst Pressure Prediction of ThinWalled, Ductile Tubulars Subjected to Axial Load," SPE Appl. Technol. Work. Risk Based Des. Well Casing Tubing, no. SPE 48327, p. 12, 1998.

6. A. G. Tallin, P. R. Paslay, O. A. Onyewuenyi, C. V. Burres, and E. P. Cernocky, "The Development of Risk-Based Burst Design for Well Casing and Tubing," Soc. Pet. Eng., no. 48320, 1998.

7. D. B. Lewis, P. R. Brand, W. S. Whitney, M. G. Hood, and M. A. Maes, "Load and Resistance Factor Design for Oil Country Tubular Goods," in Offshore Technology Conference, 1995, pp. 1-4.

8. M. A. Maes, K. C. Gulati, P. R. Brand, D. B. Lewis, D. L. McKenna, and R. C. Johnson, "Reliability-based tubing and casing design: principles and approach," $J$. Offshore Mech. Arct. Eng., vol. 119, no. 4, pp. 257-262, 1997.

9. A. J. Adams, S. H. L. Parfitt, T. B. Reeves, and J. L. Thorogood, "Casing System Risk Analysis Using Structural Reliability," in SPE/IADC Drilling Conference, 1993.

10. American Petroleum Institute, "API 5C3: Bulletin on formulas and calculations for casing, tubing, drill pipe and line pipe properties," 1992.

11. International Organization for Standardization (ISO), "ISO TR 10400: Petroleum, petrochemical and natural gas industries - Equations and calculations for the properties of casing, tubing, drill pipe and line pipe used as casing or tubing," 2004.

12. F. J. Klever, "Burst Strength of Corroded Pipe: 'Flow stress' Revisited," Offshore Technol. Conf., no. 7029, 1992.

13. G. Stewart and F. J. Klever, "Accounting for Flaws in the Burst Strength of 
OCTG," Soc. Pet. Eng., no. 48330, pp. 1-10, 1998.

14. H. Liao, Z. Guan, and G. Long, "Quantitative Risk Assessment on Safety and Reliability of Casing Strength for Oil and Gas Wells," Energy Procedia, vol. 17, pp. 429-435, 2012.

15. P. Chantose, P. Gardoni, J. Schubert, and C. Teodoriu, "Structural Reliability: Assessing the Condition and Reliability of Casing in Compacting Reservoirs," Int. Pet. Technol. Conf., no. 14297, pp. 1-15, 2012.

16. American Petroleum Institute (API), API 5C3: Bulletin on formulas and calculations for casing, tubing, drill pipe and line properties. American Petroleum Institute, 1992. 